\title{
Laughter as Same-Turn Self-Repair Initiation in L2 Oral Proficiency Interview*
}

\author{
Yan Gao \\ School of Foreign Languages, Shanxi University, Taiyuan, China \\ Email: georgina0321@163.com
}

How to cite this paper: Gao, Y. (2020). Laughter as Same-Turn Self-Repair Initiation in L2 Oral Proficiency Interview. Open Journal of Social Sciences, 8, 479-494. https://doi.org/10.4236/jss.2020.84035

Received: January 8, 2020

Accepted: April 21, 2020

Published: April 24, 2020

Copyright (c) 2020 by author(s) and Scientific Research Publishing Inc. This work is licensed under the Creative Commons Attribution International License (CC BY 4.0).

http://creativecommons.org/licenses/by/4.0/

\begin{abstract}
Repair is the effort that speaker makes to smooth utterances or conversations in order to achieve the ongoing progressivity of the turn. Among the types of repair, self-repair is mostly preferred (Schegloff et al., 1977) in talk-in-interaction, and in self-repair, self-initiated self-repair is mostly preferred, especially when it happens in the same turn. Therefore it has received much attention. In the gate-keeping interviews for Chinese candidates to get access to the target college in Britain, there occurs in L2 a large number of same-turn self-initiated self-repair cases, in which the initiation is no longer the single lexical words, or the non-lexical pauses like cut-off, or sound stretches as has been studied, but the paralinguistic device, laughter. Despite the numerous studies on roles of laughter, there is hardly a mention of laughter employed as a self-repair initiation. Consequently, this study determines on the focus on laughter as a self-repair initiator in L2, and aims to identify its exact shape and positions in self-repair and relevant repairing segment, therefore concluding on its specific functions and its relations with delicacy. This study wishes to contribute to the researches on self-repair initiation in Conversation Analysis and on laughter in particular L2 testing context.
\end{abstract}

\section{Keywords}

Self-Repair, Self-Initiated, Same-Turn, Laughter, L2

\section{Introduction}

Repair starts from the Schegloff et al.'s (1977) study in the field of sociology, and has been a focus in L2 research ever since Levelt's (1983; 1989) model of self-monitoring. Among the three main components: the repairable, repair initiation, and the repairing segment (Rieger, 2003), nearly all the previous re-

*This article is the periodical achievement of the 13th Five-year Education Planning Program (GH-18004) of Shanxi Province in China. 
searches that are relevant, agree on that different repair initiations project different repairing segment in terms of repairing contents, syntactic organization, repairing strategies etc., while the relevant studies on repair initiation are still very scarce. This study, accidentally, in the examination of data, identifies a large number of cases of same-turn self-initiated self-repair in which a particular paralinguistic device of laughter is regarded as the initiation or combined with other initiations. For instance, in Extract 1, laughter is considered the single self-initiation within same-turn self-repair.

Extract 1 (yuhong2)

15 IR: ye:s. And have you got your driving license

16 IE: $\mathrm{mm}$, not yet

17 IR: uh-huh

$18 \rightarrow$ IE: but $£ \mathrm{I}$ am on the way $(\mathrm{h}) \mathfrak{£},{ }^{\circ} \mathrm{hhuh}{ }^{\circ}$ just li-learning.

In the last line, the candidate has taken "I am on the way" as the repairable, and self initiated the repair through the laughter "hhuh", and provides the self-repair segment as "just li-learning", among which "learning" is another self-repair segment initiated by the cut-off after "li". However, in some cases, laughter is not the single initiation as in Extract 2.

Extract 2 (Le qianyue2)

15 IR: And (1.8) what's uh: (.) >do you think, is there any<changes in terms of (.) uh, male

16 and female relations in the countries, and on the status of (.) men and women.

17 IE: Ah, yeah, I think it proved a lot, the nowadays=

18 IR: $=$ uh-huh=

...

26 IE: And now, overlike me: uhm, you know, (0.3) usually we don't have the quality to go:

27 universities in the- $>$ in the $<$ past $=$

28 IR: $=\mathrm{hm}=$

29 IE: Now its changed=

30 IR: $=\left[{ }^{\circ}\right.$ yes ${ }^{\circ}$

$31 \rightarrow$ IE: [You know, every student have the equal rights to-to know, to to to, go-, to go-, to-er,

$32 \rightarrow$ huhhh $£$ sorry, to go universities£, or even to go abroad $=$

33 IR: =yes, yes.

The candidate has produced many times of self-repair in line 31 and 32 of this case. In the last time, he combined the cut-off, the delay "er", the laughter "huhh", and the lexical apologizing "sorry" together to initiate the repair for the last repairable "to-". Though the repairing segment "to go universities" is not correct in grammar, the self-repair is complete in the same turn. And the laughter is prominent in the roles of initiation not only for its single existence, but for its spread to the apologizing words and the repairing segment.

Considering the fact that laughter has seldom been regarded as an initiation in 
previous researches, this study, based on the specific data, determines to treat laughter as the target in terms of its particular function in self repair.

\subsection{Self-Initiated Self-Repair}

According to Schegloff et al. (1977), repair is the treatment of recurrent problems in speaking, hearing, and understanding talk-in-interaction. It mainly involve three components: the repaired segment containing the repairable, repair initiation and the repairing segment (Rieger, 2003: p. 48) or. Schegloff et al. (1977) has separated repair into four main types: self-initiated self-repair, other-initiated self-repair, self-initiated other-repair, and other initiated other-repair. Among them, speakers are found to have the preference for self-repair and self-initiation in talk-in-interaction. Therefore, it is necessary to explicate it in details.

Self-repair has been in the long run a research focus in psycholinguistics, applied linguistics and second language acquisition. Psycholinguistically-oriented linguists (e.g., Levelt, 1983; Schade et al., 2003) take into account whether self-repair is carried out before the problematic part of the utterance has actually been articulated, i.e., during early stages of speech production planning. Linguistically-oriented researchers consider the term self-repair to cover those instances where syntax is manipulated (e.g., Fox \& Jasperson, 1995: p. 81). Levelt’s (1983, 1989) once made the most comprehensive taxonomy of self-repairs in the psycholinguistic approach, i.e. covert and overt repairs. As Levelt (1983: p. 55) points out, "covert repairs are problematic data in that it is always impossible to determine what the speaker is monitoring for ...", which occur normally prearticulatorily and may be characterized by just an interruption with an editing term, or the repeat of one or more lexical items. And overt repairs are made normally after the trouble has been articulated, which involve different repairs (D-repairs), error repairs (E-repairs) and appropriateness repairs (A-repairs). Besides that, Levelt proposed the famous self-monitoring mechanism of one's own speech, which contributes greatly to the field of second language acquisition.

Findings of self repair in the L2 field so far not only concern about the differing types of L2 self-repair (e.g. VanHest, 1996a; Kormos, 1999; Postma \& Kolk, 1993), various self-repair strategies (e.g. Ma \& Gao, 2018), and detailed studies on prosodic features (e.g. Ling \& Chen, 2012) and different means of initiation with its repair solutions (e.g. Rieger, 2003; Laakso \& Sorjonen, 2010) in distinct languages, etc.

Self-initiated self-repair is the most common type of repair. Schegloff et al. (1977) were the first to investigate and describe systematically self-initiated same-turn self-repair in conversations, in which repairable and repairing segments occur in the same turn and the repair is performed by the initiator of the repairable. In order to avoid interactional trouble, the speaker, more precisely the speaker's monitor (Levelt, 1983, 1989), needs to detect these problems in the not-yet-produced phonetic plan or in already articulated parts of the utterance 
and repair them. Van Hest $(1996,2004)$ provides the similar definition as well. Birkner, et al. (2012: p. 1415) once proposed the definition of same-turn self-initiated self-repair when explaining retracing as:

When retracing, the speaker can, apart from a fresh start, reactivate a previous syntactic slot and apply different repair strategies, ranging from single repetitions, substitutions, insertions, and deletions to multiple retractions or various combinations of repair types. Retractions that aim at solving any kind of problem occurring in speech production by manipulating the syntactic structure of the utterance in one of the four ways mentioned above (i.e., repetition, substitution, insertion, deletion), are called same-turn self-initiated self-repairs.

Considering the environment of the same-turn self-repair, Schegloff (2014) distinguishes macro-projection and micro-projection and refers to micro-projection as the local environment tailored, shaped and interpreted by reference to the developing project of the overall structural organization, while the macro-projections are always realized by progress at the local, bit-by-bit organization. The TCUs and turns overwhelmingly (but not exclusively) in the same-turn are the environment for self-repair, as he explains, and these repairs, in one way or another, intervene to interrupt the progressivity of the talk. Schegloff (2014) goes on to explain same-turn self-initiated self-repair in terms of ten operations, i.e. replacing, inserting, deleting, searching, parenthesizing, aborting, sequence-jumping, recycling, reformatting, and reordering.

\subsection{Repair Initiation}

Among the three components of repair, Rieger (2003: p. 48) regards the repairable as not necessarily audible, but can be inferred from the presence of repair initiation, repair initiation as a "possible disjunction with the immediately preceding talk" (Schegloff, 2000: p. 207), and the repairing segment, as repairing the trouble that the speaker has perceived.

The most common location of repair initiation, according to Schegloff (1979), is just after the start of a turnconstructional unit (post-initiation) or just before its completion (pre-completion), for example, in the case of a word after its first sound or just before its last sound (Schegloff, 1979: p. 275). The relevant domain for the post-initiation (or post-beginning, as Fox et al., 2009 term it) of a unit starts after the first sound is recognizable and continues until the first sound is complete; whereas the relevant domain for pre-completion begins just before the final sound is articulated, and continues until just before the final sound is complete (Fox et al., 2009: p. 65). The term recognizable completion has been introduced by Fox et al. (2009). Repair initiation at recognizable completion refers to initiations in or after the last sound of the word (Fox et al., 2009: p. 71), though different languages have very diverse morphosyntactic profiles in self-repair initiations.

Repair initiation consists of a lexical or non-lexical initiation, or it may be 
non-observable as well. In English, lexical initiation (Laakso \& Sorjonen; 2010) could be implying alternatives (e.g. or), parenthetic explanation/specification like (e.g. I mean), apologizing (e.g., oops and sorry) and repetition as vocalized fillers (e.g. Bada, 2010). And in L2 field for Chinese learners, lexical initiation could involve "I mean", "well", "rather", or "that is" (Ran, 2003). Non-lexical initiation could be pauses, sound stretches, and quasi-lexical vocalizations such as uh/um (Schegloff et al., 1977: p. 367; Levelt, 1983), cut-off or particles (Laakso \& Sorjonen, 2010; Clift, 2016).

These repair initiations may serve to display trouble awareness, therefore may result in necessary revisions of both form and content of the talk (Nyroosa, et al. 2017). Particularly in code-switch context, it may amplify test-takers' attention to what needs to be replaced or revised, and indicates to co-participants that self-repair is underway. The practice helps push forward turn transition and pre-empts conclusions about the speaker's stance or linguistic competence, which may be particularly relevant in a language testing context. According to Clift (2016), self-repair can reshape the trajectory of the emerging sequence and in institutional setting, there are accounts of how self-repair reduces the accountability of an interviewer in an avoiding excessively coercive forms of questioning and mitigates displays of entitlement.

However, these studies are just some mentions. Researches on means of initiation are still scarce, especially on self-initiator, and deserve further attention in that these means may differ in their capacity to project different types of repair initiated. For example, a negation word "no" may project a replacement of an error both in Dutch (Levelt, 1983: pp. 71-72) and in English conversations (Sparks, 1995: p. 174). The initiator "I mean" in English is used to initiate a replacement (Sparks, 1995: p. 174) or an abandonment of the turn-constructional unit that has already been produced (Jasperson, 1998: p. 101).

\subsection{Laughter}

Since Jefferson's work $(1977 ; 1984 ; 1985)$ on laughter, the social organization of laughter within talk has been researched within conversation analysis over a number of years. His conclusion (1977) about the sequential organization of laughter is very preliminary and fundamental, which involves, for instance, when people laugh together, they are not necessarily laughing in unison, and when speech and laughter are continuous, quite routinely laughter will stop immediately after speech starts. After that, a great strand of studies has been based on that and further explores the detailed organization of laughter in sequence and its roles in sequential progressivity. As in Holt's (2010) finding, both the occurrence and absence of laughter at an appropriate juncture may result from orientation to interactional considerations such as the ongoing trajectory of the talk. Apart from that, laughter is also identified as full of functions in reflecting roles and relations of participants. For instance, Glenn (2010) proposes that in institutional setting, the asymmetries of laughter from interviewer and interviewee could disclose the hegemony of the their roles, which is consistent with 
doctor-patient interactions (Haakana, 2001; 2002), and Gao \& Wu (2018) identifies the use of single laughter doing alignment and affiliation in response to prior actions when participants are not competent enough in L2 testing context, which not only shed lights to Chinese candidates' linguistic competence, but reflects their tendency to build relational solidarity. Potter and Hepburn (2010) also regards laughter, in terms of IPA (interpolated particles of aspiration), as the devise to signal "possible trouble in the use of the word or there is more going on than the mere use of the word would indicate" and IPA can be "inserted into lexical items within turns to fitness or modulate the action that is produced in some way".

Laughter is viewed as closely related to delicacy as well in most literatures. It is regarded as a mark of their delicacy and the device to deal with delicate moments. Delicacy could involve the patients' reluctance to tell their situations or disagreement with doctors' utterance (Haakana, 2001; 2002) and aphasic speaker's incompetence (Wilkinson, 2007), children' unwilling or incompetent to parents' speaking (Walker, 2017), and interviewees' nervousness in self-directed assessing and knowing, self-boasting, managing insufficient answer (Glenn, 2013a) and their handling the conflict of avoiding self-praise and offering preferred response when complimenting (Gao \& Wu, 2018). Goffman (1956) once describes the "hollow laugh" as one method of trying to conceal embarrassment, and Adelsward (1989), suggests that "embarrassed laughter" can be an attempt to save face. Therefore, laughter when occurring in talk-in-interaction is sociolinguistically significant.

\subsection{Research Gap}

While laughter in previous studies has been proved instrumental and tactful in achieving sequential progressivity, reflecting institutional identities and relations, modulating action, dealing with delicacy, and fulfilling sociolinguistic functions, it still needs to be further explored in details in terms of its specific position in the whole talk-in-interaction, due to the findings that different sequential positions demonstrates exactly different functions or differing levels of functions. Besides that, laughter has seldom been discussed as an initiation in the same-turn self-repair. However, in this study of the particular L2 testing environment in which linguistic and interactional competences are targeted, laughter occurs frequently in the position between the post-initiation and pre-completion of the same-turn self repair, which is defined as self-repair initiation.

Consequently, based on the importance and shortage of researches on self-repair initiation and the particular data of laughter that occurs as the self-repair initiation, this study aims to examine the data and make a clear classification of those laughter in terms of exact positions, prosodic features, consequent repair segment, and decides on their functions and relations with delicacy, wishing to contribute to the study on self-repair initiation in Conversation Analysis and on laughter in particular L2 testing context. 


\section{Data and Methodology}

This study has recorded audibly around 260 minutes' interviews which involve one interviewer from an English-as-native-language country and 23 candidates from China. Those candidates are mostly junior students from a certain Chinese college and have just passed IELTS. Those interviews were conducted within two and a half days, with a purpose to decide whether those candidates are competent in getting enrolled in the target college in terms of their linguistic proficiency, so the interview is a gate-keeping test. Each interview involves three parts: free conversation, self-presentation and the following questions about the self-presentation. The 9 Extracts in this article are exactly examples from these three parts of the interviews.

Methodologically, this study is built on the basic distinction of self and other repair and that of self and other initiation made by Schegloff et al. (1977) in CA. The former refers to different performer who does the repairing, and the latter refers to different performer who does the initiation. The former may occur consecutively in the same turn, i.e. the repairable, self-initiation, and self-repair segment, or in different next turns, while the latter, other repair or other initiation could only happen in the next turn, since it is from the other speaker. Though other initiation could also project self-repair, this study particularly selects those self-initiated self-repair turns as the focus in which laughter is employed between the post-initiation and pre-completion of the same turn, according to Fox, et al. (2009) or between the repairable and the repairing segment according to Rieger (2003). These turns mostly occur in the Candidates' response to interviewer's question. This study then transcribed those question-and-answer sequence systematically and strictly according to Jefferson's (1974, 1985) and Glenn and Holt's (2013b) standard, under the aid of "audacity" software, and received the recognition and agreement of the Chinese DIG workshop members in great details.

\section{Data Analysis}

Findings of this study has shown that laughter basically has three types of existence as same-turn self-repair initiation: 1) it occurs as the single initiation, i.e. between the repairable and the repairing segment; 2 ) it occurs with other initiation like delay, pause, cut-off or the lexical words; 3 ) it occurs simultaneously with the repairing segment or with the whole repair process. The first existence is the most frequent one according to the data and therefore will be dealt with in the first place. IR in all the extracts refers to the interviewer and IE refers to the interviewee or the candidate in the interview. And the line in which self-repair is performed is marked with an arrow.

\subsection{Laughter Occurs as the Single Initiation}

Self-repair self-initiation as one type of repair initiation in the same turn, according to Schegloff (2000: p. 207), is also a "possible disjunction with the im- 
mediately preceding talk" and it, most frequently in this data, occurs between the repairable and repairing segment and becomes the single initiation, as Extract 3 shows.

Extract 3: (4)

20 IE: so (.) I think people in here are very friendly,

21 IR: $[\mathrm{hm}$

22 IE: [I think. but I-I want to go back my hometown. [yeah

23 IR: [ah: why-why is that?

24 IE: $\mathrm{mm}$, I don't think it's the air-pollution, air-air environment is very(.) dangerous.

25 IR: hm, [mm

$26 \rightarrow$ IE: [danger, I can't, huhhh, I can't ( )

27 IR: right.

The candidate is responding to the interviewer's question "why do you want to go back to your hometown" from line 24 to 26 in this case. In line 26, he stops after the utterance "I can't", and launch a new TCU "I can't ( )", by means of recycling (Schegloff, 2014), though the utterance in the bracket is not that clear. It could be inferred that the single laughter with closed vowel sound and relatively longer outbreath ( $3 \mathrm{~h}$ ) between the two "I can't" serves as the self-initiator in the self-repair. Levelt (1983) takes that as "C-repair" (covert repair), which occur when speakers discover trouble and interrupt themselves before the troubled item is uttered.

However, laughter is usually contagious and may start early before the initiation or continue until after the initiation, as in the first extract.

Extract 1 (yucong2)

15 IR: ye:s. And have you got your driving license

16 IE: $\mathrm{mm}$, not yet

17 IR: uh-huh

$18 \rightarrow$ IE: but $\mathfrak{E I}$ am on the way $(\mathrm{h}) \mathfrak{E},{ }^{\circ}$ hhuh ${ }^{\circ}$ just li-learning

When he expresses "on the way" in line 18, the candidate has already realized the incorrectness of the phrase and plans laughter along with the repairable. Therefore the simultaneous and the single soft laughter together are treated as the self-initiation. "just lilearning" is the replacement of the expression "on the way", which results in an Error-repair.

And besides the single one, laughter could spread to the repairing segment as well as in Extract 4.

Extract 4: (14)

10 IR: how do you think this problem can be avoided

11 IE: erm, actuall, erm, er, I think to be workaholic is, is not very bad, but, this is not the

12 things, if this is not things I really want to do,

13 IR: uh-huh

14 IE: I, the wise things to do, I don't like to put a lot of time to them,

15 IR: uh-huh 
16 IE: I want to do something, er is really useful, helpful, have a great help to others

17 IR: uh-huh

18 IE: this, I am, do a kind of things, I will try my best to do, if the things is boring, useless, or

$19 \rightarrow$ something maybe criminal, no use, I think it's really huh huh, £waste my timef.

20 IR: alright

The candidate, in responding to the question of line 10, has continued in many turns and concludes his answer in line 19, by saying "it's really waste my time". The two particles of laughter characterized by closed " $u$ " sound happens between the repairable "I think it's really" and the searching solution "waste my time", though not grammatically exact, and therefore functions as the self-initiator. The simultaneous laughter with the repairing segment could be understood as the continuity of laughter or the linguistic insufficiency of the solution.

Those previous extracts have employed different operations, according to Schegloff (2014), to make the self-repair involving replacing, recycling and searching, and they concern about different types of repair in L2 study, based on Levelt's (1983) classification, like Error repair and Covert repair. However, what all the three self-repairs concern about is basically linguistic matters rather than pragmatic competence, which may display their knowledge of language use, such as the exactness or the appropriateness. Extract 5 indicates a self-repair of such a type.

Extract 5 (wangyuan20)

13 IR: have you been abroad before?

14 IE: mm, no, huhh

15 IR: no?

$16 \rightarrow$ IE: oh, yes, when I was young, [huhh, huhhh when I was $£$ so young£,

17 IR: [oh::

18 IE: I go to the (0.3) Japanese, but I forgot, with my friend,

19 IR: ah:::

The self-repair of this case occurs in line 16, as a whole repair segment to the repairable of line 14, which is initiated by the other speaker with "no". When he is doing the self-repair, the candidate uses two laughter particles of closed vowel sound and relatively longer out breath than that in Extract 4 to initiate the repairing segment. It displays his trouble awareness that only the word "young" is not that exact and appropriate, and therefore he works out a more exact and appropriate expression by inserting "so" for the solution. The candidate has employed a different strategy to make necessary revision of content rather than form (Nyroosa, et al. 2017), which is A-repair (appropriateness repair), as Levelt (1983) described, therefore shows a relatively higher degree of linguistic proficiency. 


\subsection{Laughter Occurs with Other Initiation}

Among the data of self-initiated self-repair in this study, there occur also a number of cases with both laughter and other non-lexical means or devices as the joint initiators, as shown in Extract 6.

Extract 6 (liujing15)

06 IE: I want to introduce myself

07 IR: ok

$08 \rightarrow$ IE: I was born in Taiyuan, my mother is a Taiyuan, hehhh, er my mother was born in

09 Taiyuan.

10 IR: uh-huh

The candidate in this case has detected the linguistic errors in the expression "my mother is a Taiyuan" in line 8 and fails in searching for the correct word. Therefore, he reformats the expression and changes it to the passive voice, which testifies the Error repair, based on Levelt's (1983) classification. Between the repairable and the passive expression, laughter occurs first as the initiator, with "e", a comparatively open vowel sound and long aspiration (3h), and after that, a further delay "er", as one of quasi-lexical vocalizations (Schegloff et al., 1977: p. 367; Levelt, 1983) is used for the same function, which proves a need for longer reaction time.

Laughter could not only be combined with one initiator, or non-lexical initiators, but with lexical words and more initiators. Extract 2, as previously mentioned, presents a good example.

Extract 2 (he qianyue2)

15 IR: And (1.8) what's uh:(.) >do you think, is there any< changes in terms of (.) uh, male

16 and female relations in the countries, and on the status of (.) men and women.

17 IE: Ah, yeah, I think it proved a lot, the nowadays=

18 IR: $=$ uh-huh=

...

26 IE: And now, overlike me: uhm, you know, (0.3) usually we don't have the quality to go:

27 universities in the- $>$ in the $<$ past $=$

28 IR: $=\mathrm{hm}=$

29 IE: Now its changed=

30 IR: $=\left[{ }^{\circ}\right.$ yes ${ }^{\circ}$

$31 \rightarrow$ IE: [You know, every student have the equal rights to to know, to to to, go-, to go-, to-er,

$32 \rightarrow$ huhhh £sorry, to go universities£, or even to go abroad=

33 IR: =yes, yes.

It is not hard to discover in line 31 and 32, the delaying vocalization "er", the laughter "huhh", and the apologizing words "sorry" are combined one after 
another to initiate the last repairing segment. The laughter shares the similar prosodic contour with that in Extract 6, except for the closed "u" vowel sound and it is continuous until the end of the repairing segment. Considering the fact that it's an Error repair by means of repetitions of too many times to search for the word and the fact that the last repairing solution "to go universities" is still grammatically incorrect, we may have an understanding of the candidate's linguistic proficiency or his state of nervousness at that particular time. Besides that, the linguistic competence may also be demonstrated in some degree by initiators of code-switch, i.e. lexical words of other language except English. Extract 7 is a typical example.

Extract 7 (wangyuan21)

30 IR: do your parents go abroad

$31 \rightarrow$ IE: yes, my father, er, bushi, huhhh, sorry, nege, my sister were study at Glasgow university

32 IR: oh

33 IE: three years, and...

In responding to the question of line 30, the candidate abort the expression "yes, my father" and make the D-repair (different information repair) in the same turn. Between them the candidate has failed in a series of initiating in line 31 by producing the quasi-lexical delaying "er", twice code switch words "bushi" (which means not in Chinese) and "nege" (which means this or that in Chinese), single laughter and apologizing word "sorry". This fresh start and multiple means of initiation in one self-repair indicates the candidate's hesitation and difficult in searching for the solution and the particular code switch into his native language further demonstrates his lack of confidence in expressing himself.

\subsection{Laughter Occurs Along the Repairing Segment or the Whole Repair Process}

Due to the continuity and contagiousness of laughter, as previously mentioned, laughter could spread from the repairable to the repairing segment, and even more than that. In those situations, laughter does not exist independently, if anything, it only accompanies the process. Therefore it is hard to confirm the initiating function of laughter directly and simply. Rieger (2003) even believes that repair initiation could be non-observable in certain cases of repetitions. However, Schegloff et al. (1977) insists that 'every feature used by a speaker that interrupts or disturbs the smooth flow of his or her speech can be listed under the heading of "possible self-initiated same-turn self-repair". We consequently have to take a closer look at detailed repair TCUs or turn in each case. For instance, in Extract 8, laughter spread only along with the repairing segment.

Extract 8 (9)

25 IR: uh, are there many women ministers,

26 IE: $\mathrm{mm}:$ : (tch) in fact, er: at one (0.4) period, just have one (0.4) er woman can be minister,

$27 \rightarrow$ because (.) >that just like rules $\uparrow<£$ rules made by men£, hh 
28 IR: $\mathrm{mm}$.

In line 27, the candidate has elevated his tone and stressed his pronunciation on "just like rules", but he still detects the inappropriateness and inaccuracy of "rules" and goes on to refine it as "rules made by men". This A-repair, by means of inserting, illustrates in details his viewpoints of the inequality of men and women. The simultaneous laughter occurs at the very time of his realization of the inappropriateness and spreads along the whole solution, which has slowed down, compared with the repairable, and makes laughter a prominent feature, let alone the continuous laughter alone in the end. Since no other features is observable here, it is reasonable to conclude that laughter exists as the result of his realization and therefore plays the role of launching the repairing segment. And the simultaneous laughter meanwhile mitigates the inappropriateness of the repairable so as to make up for his viewpoints and his linguistic performance. Let's take another example, Extract 9, for a closer look, in which laughter spreads along the whole repair process.

Extract 9 (liujing15)

08 IE: I was born in Taiyuan, my mother is a Taiyuan, hehhh, er my mother was born in

09 Taiyuan.

10 IR: uh-huh

$11 \rightarrow$ IE: so, $£$ I like it, I like here£ though it is dirty.

12 IR: $\mathrm{mm}$

This is a typical E-repair example in which "it" is replaced by "here" in line 11. It presents an example of self-repair without obvious initiator between the repairable "I like it" and the repairing segment "I like here", while laughter occurs simultaneously along the whole repair process. It is the only feature among the non-lexical initiations that we can observe apart from the other two components of repair. If it is understood as the realization of error, the laughter could be taken as the repair initiator, for speakers normally makes his oral plans before the real production, while if it is understood as emotional display for his likeness, it is not. Then the initiator of this self-repair is somewhat non-observable. It is a confusing exception and too hasty to draw a conclusion about the role of laughter in these similar situations.

\section{Discussion}

In terms of structural organization of initiator in same-turn self-repair, laughter could be either a single existence between the repairable and the repairing segment with more or less particles, or an accompanying non-linguistic feature along the repairable or the repairing segment, or even the whole repair process. The reason why the speaker laughs before the position of the initiator is possibly that human have the mental capacity to plan his speech seconds before the real production (Levinson, 2016) and therefore when he realized the trouble in his utterance, linguistically or pragmatically, he may yield laughter along with the 
repairable. And laughter could spread to the repairable segment as well due to the feature of continuity of its prosodic features and it will not interrupt the linguistic production as accompanying para-language. However, in the last situation when laughter exists only as an accompanying device along with the whole repair process, it is yet not certain to assert the role of laughter as an initiator. When laughter occurs with other means of initiator, it is relatively flexible among these means, for that the laughable could be overlapping with various troubles, such as the repairable in Extract 6, many repetitions of failure to initiate in Extract 2, and code-switch to his native language in Extract 7.

Considering its role of laughter, sociologists (e.g. Goffman, 1956; Adelsward, 1989) have confirmed that laughter could be used to conceal embarrassment and to save face. In institutional interaction, laughter from the speakers who do not represent institutional identities, may indicate their inferior positions and stance to build solidarity, such as in Haakana's $(2001,2002)$ medical conversations between doctors and patients and in Glenn's (2013a) employment interviews. The hollow laughter or the embarrassed laughter from the candidates, on one side, shows their intentions to disguise their insufficiency and on the other, to build good relations in order to get access to the target school. In sequence, Glenn (2013a) proposes that laughter modifies or modulates the talk that it targets. Particularly in this study, laughter in the same turn as the laughable is defined as "first position" laughter. Thus, the first-position laughter is used to signal that the speaker is aware of a tension between what he says, how this could be interpreted by others and what he means. And laughter in employment interviews allows interviewees to make positive but modest claims about self (Glenn, 2013a). Based on that, laughter of this study could have two main divisions: one is the result of linguistic incompetence and the other is mostly the result of inappropriateness or inexactness. For instance, in Extract 6, the candidate's linguistic failure in producing "Taiyuaner" has made him reformat the syntactic organization into a passive one and the error of the expression "on the way" in Extract 1 has been replaced by "just learning". On the other hand, Extract 5 and 8 clearly demonstrate the inappropriateness or inexactness of the original expression by inserting "so" to "when I was young" and "rules made by men" to "just like rules". These linguistic incompetence and pragmatic inappropriateness are exactly one sort of delicacy. The candidates in this interview intend to mark this delicacy and mitigate the errors or the inappropriateness of their oral production by means of laughter and conceal their embarrassment in linguistic proficiency and to save face, though from interviewer's perspective, laughter may be an indicator of their insufficiency.

Since laughter may be an indicator of the candidates' linguistic proficiency, we may reach a conclusion based on the data of this study that the existence of laughter as initiator mostly happens in the talk-in-interaction of the participants with weak linguistic proficiency, which has been triangulated by Wilkinson's (2007) studies on aphasic patients and Walker's (2017) study on children's talk 
with their parents. Particularly in this study, the weak performance of the Chinese candidates could be demonstrated in five aspects: 1) as in Extract 2, the repair has been initiated many times and with many means of initiations like cut-off, laugh, or delaying vocalization before it is repaired; 2) the repairing segment for most times are concerned about the syntactic or other grammar problems, as in Extract 1 and 6; 3) the repairing segment after being repaired is still grammatically incorrect, as in Extract 2 and 9; 4) according to Levelt's (1983) classification, the Overt repairs (involving D-repair, E-repair, and A-repair) are greatly more than the Covert repairs, which normally do not include obvious mistakes and among the three types of the Overt repairs, the number of E-repair is the top one; 5) code-switch back into one's mother tongue is also an evidence to display speaker's trouble awareness and their competence in the target language (Nyroos, et al. 2017). The second to the fourth aspects are all concerned about the repair content. Schegloff et al. (1977) and Kasper (1985) once made the similar comments that within the conversation between native speakers and non-native speakers, most self-repairs are error correction, which focus on phonetics, morphology, or other grammar matters, rather than pragmatic repair which focus on the topic or the appropriateness. Nonetheless, all these performances that deal with laughter may help interviewers pre-empts conclusions about the speaker's stance or linguistic competence in a language testing context.

\section{Conflicts of Interest}

The author declares no conflicts of interest regarding the publication of this paper.

\section{References}

Adelsward, V. (1989). Laughter and Dialogue: The Social Significance of Laughter in Institutional Discourse. Nordic Journal of Linguistics, 12, 107-136. https://doi.org/10.1017/S0332586500002018

Bada, E. (2010). Repetitions as Vocalized Fillers and Self-Repairs in English and French Interlanguages. Journal of Pragmatics, 42, 1680-1688. https://doi.org/10.1016/j.pragma.2009.10.008

Birkner, K., Henricson, S., Lindholm, C., \& Pfeiffer, M. (2012). Grammar and Self-Repair: Retraction Patterns in German and Swedish Prepositional Phrases. Journal of Prag matics, 44, 1413-1433. https://doi.org/10.1016/j.pragma.2012.06.003

Clift, R. (2016). Don't Make Me Laugh: Responsive Laughter in (Dis)affiliation. Journal of Pragmatics, 100, 73-88. https://doi.org/10.1016/j.pragma.2016.01.012

Fox, B., \& Jasperson, R. (1995). A Syntactic Exploration of Repair in English Conversation. In P. Davis (Ed.), Descriptive and Theoretical Modes. The Alternative Linguistics (pp. 77-134). Amsterdam: John Benjamins. https://doi.org/10.1075/cilt.102.04fox

Fox, B., Wouk, F., Hayashi, M., Fincke, S., Tao, L., Sorjonen, M., Laakso, M., \& Hernandez, W. F. (2009). A Cross Linguistic Investigation of the Site of Initiation in Same-Turn Self-Repair. In J. Sidnell (Ed.), Conversation Analysis: Comparative Perspectives (pp. 60-103). Cambridge: Cambridge University Press. https://doi.org/10.1017/CBO9780511635670.004 
Gao, Y., \& Wu, Y. X. (2018). Laughter as Responses to Different Actions in L2 Oral Proficiency Interview. Open Journal of Modern Linguistics, 8, 1-22.

https://doi.org/10.4236/ojml.2018.86018

Glenn, P. (2010). Interviewer Laughs: Shared Laughter and Asymmetries in Employment Interviews. Journal of Pragmatics, 42, 1485-1498.

https://doi.org/10.1016/j.pragma.2010.01.009

Glenn, P. (2013a). Interviewees Volunteered Laughter in Employment Interviews: A Case of "Nervous" Laughter? In P. Glenn, \& E. Holt (Eds.), Studies of Laughter in Interaction (pp. 255-275). London: Bloomsbury.

Glenn, P., \& Holt, E. (2013b). Studies of Laughter in Interaction. London: Bloomsbury.

Goffman, E. (1956). Embarrassment and Social Organization. In E. Goffman (Ed.), Interaction Ritual: Essays on Face to Face Behaviour (pp. 97-112). Harmondsworth: Penguin. https://doi.org/10.4324/9780203788387-4

Haakana, M. (2001). Laughter as a Patient's Resource: Dealing with Delicate Aspects of Medical Interaction. Text, 21, 187-219. https://doi.org/10.1515/text.1.21.1-2.187

Haakana, M. (2002). Laughter in Medical Interaction: From Quantification to Analysis, and Back. Journal of Sociolinguistics, 6, 207-235.

https://doi.org/10.1111/1467-9481.00185

Holt, L. (2010). The Last Laugh: Shared Laughter and Topic Termination. Journal of Pragmatics, 42, 1513-1525. https://doi.org/10.1016/j.pragma.2010.01.011

Jasperson, R. (1998). Repair after Cut-Off: Explorations in the Grammar of Focused Repair of the Turn-Constructional Unit-So-Far. Unpublished PhD Thesis, Boulder, CO: Department of Linguistics, University of Colorado.

Jefferson, G. (1974). On the Organisation of Laughter in Talk about Troubles. In J. Atkinson, \& H. J. Maxwell (Eds.), Structures of Social Action: Studies in Conversation Analysis (pp. 346-369). Cambridge: Cambridge University Press.

https://doi.org/10.1017/CBO9780511665868.021

Jefferson, G. (1985). An Exercise in the Transcription and Analysis of Laughter. In T. A. V. Dijk (Ed.), Handbook of Discourse Analysis (pp. 25-34, Vol. 3). London: Academic Press.

Jefferson, G., Sacks, H., \& Schegloff, E. (1977). Preliminary Notes on the Sequential Organization of Laughter. Pragmatics Microfiche. Cambridge: Cambridge University, Department of Linguistics.

Kasper, G. (1985). Repair in Foreign Language Teaching. Studies in Second Language Acquisition, 7, 200-215. https://doi.org/10.1017/S0272263100005374

Kormos, J. (1999). Monitoring and Self-Repair in L2. Language Learning, 49, 303-342. https://doi.org/10.1111/0023-8333.00090

Laakso, M., \& Sorjonen, M. (2010). Cut-Off or Particle-Devices for Initiating Self-Repair in Conversation. Journal of Pragmatics, 42, 1151-1172.

https://doi.org/10.1016/j.pragma.2009.09.004

Levelt, W. J. M. (1983). Monitoring and Self-Repair in Speech. Cognition, 14, 41-104. https://doi.org/10.1016/0010-0277(83)90026-4

Levelt, W. J. M. (1989). Speaking: From Intention to Articulation. Cambridge, MA: MIT Press.

Levinson, S. C. (2016). Turn-Taking in Human Communication-Origins and Implications for Language Processing. Trends in Cognitive Sciences, 20, 6-14.

https://doi.org/10.1016/j.tics.2015.10.010 
Ling, L., \& Chen, H. (2012). The Self-Repair Prosodic Features in the Dialogues of Chinese EFL Learners. Foreign Languages and Their Teaching, 4, 35-39.

Ma, W., \& Gao, Y. (2018). A Study on the Same-Turn Self-Repair in Chinese Doctor-Patient Interaction. Journal of Foreign Languages, 41, 42-54.

Nyroos, L., Sandlund, E., \& Sundqvist, P. (2017). Code-Switched Repair Initiation: The Case of Swedish Eller in L2 English Test Interaction. Journal of Pragmatics, 120, 1-16. https://doi.org/10.1016/j.pragma.2017.08.008

Postma, A., \& Kolk, H. (1993). The Covert Repair Hypothesis: Prearticulatory Repair Processes in Normal and Stuttered Disfluencies. Journal of Speech and Hearing Research, 36, 472-487. https://doi.org/10.1044/jshr.3603.472

Potter, J., \& Hepburn, A. (2010). Putting Aspiration into Words: "Laugh Particles", Managing Descriptive Trouble and Modulating Action. Journal of Pragmatics, 42, 1543-1555. https://doi.org/10.1016/j.pragma.2009.10.003

Ran, Y. P. (2003). A Pragmatic Account of the Discourse Marker WELL. Journal of Foreign Languages, 3, 58-64. https://doi.org/10.1016/S0378-2166(01)00060-1

Rieger, C. L. (2003). Repetitions as Self-Repair Strategies in English and German Conversations. Journal of Pragmatics, 35, 47-69.

Schade, U., Berg, T., \& Laubenstein, U. (2003). Versprecher und ihre Reparaturen. In G. Rickheit, T. Hgerrmann, \& W. Deutsch (Eds.), Psycholinguistik-Psycholinguistics (Handbücher zur Sprach-und Kommunikationswissenschaft) (pp. 317-338). Berlin: Mouton de Gruyter.

Schegloff, E. A. (1979). The Relevance of Repair to Syntax-for-Conversation. In T. Givon (Ed.), Syntax and Semantics 12: Discourse and Syntax (pp. 261-286). New York: Academic Press. https://doi.org/10.1163/9789004368897012

Schegloff, E. A. (2000). When “Others” Initiate Repair. Applied Linguistics, 21, 205-243. https://doi.org/10.1093/applin/21.2.205

Schegloff, E. A. (2014). Ten Operations in Self-Initiated, Same-Turn Repair. In M. Hayashi, G. Raymond, \& J. Sidnell (Eds.), Conversational Repair and Human Understanding (pp. 41-70). Cambridge: Cambridge University Press. https://doi.org/10.1017/CBO9780511757464.002

Schegloff, E. A., Jefferson, G., \& Sachs, H. (1977). The Preference for Self-Correction in the Organization of Repair in Conversation. Language, 53, 361-382.

https://doi.org/10.1353/lan.1977.0041

Sparks, R. (1995). The Structure of Self-Repair in English Conversation. Unpublished $\mathrm{PhD}$ Thesis, Boulder, CO: Department of Linguistics, University of Colorado.

Van Hest, H. E. (1996). Self-Repair in L1 and L2 Production. Tilburg: Tilburg University Press. https://doi.org/10.1075/itl.117-118.05van

Van Hest, H. E. (2004). The Relationship between Self-Repair and Language Proficiency. http://www.asha.ucf.edu/vanhest2.html

Walker, G. (2017). Young Children's Use of Laughter as a Means of Responding to Questions. Journal of Pragmatics, 112, 20-32. https://doi.org/10.1016/j.pragma.2017.02.006

Wilkinson, R. (2007). Managing Linguistic Incompetence as a Delicate Issue in Aphasic Talk-in-Interaction: On the Use of Laughter in Prolonged Repair Sequences. Journal of Pragmatics, 39, 542-569. https://doi.org/10.1016/j.pragma.2006.07.010 